\title{
Efficacy and Safety Profile of Preservative Free Brimonidine 0.2\%/Timolol 0.5\% Fixed Dose Combination (BTFC) vs Benzalkonium Chloride (BKC) Preserved Brimonidine 0.2\%/Timolol 0.5\% Fixed Dose Combination: A Prospective Study
}

\author{
Divya Tara ${ }^{1}$, Gursatinder Singh ${ }^{1}$, Suresh Kalra ${ }^{2}$, Anand Aggarwal ${ }^{1 *}$, \\ Ishwar Singh ${ }^{1}$, Neetu Sharma ${ }^{3}$ and Talvir Sidhu ${ }^{1}$ \\ ${ }^{1}$ Department of Ophthalmology, Government Medical College, Patiala, Punjab, \\ India \\ ${ }^{2}$ Director, Kalra Eye Hospital Yamunanagar, Haryana, India \\ ${ }^{3}$ Department of Pharmacology, Government Medical College, Patiala, Punjab, India \\ *Corresponding Author: Anand Aggarwal, Department of Ophthalmology, \\ Government Medical College, Patiala, Punjab, India.
}

Received: February 18, 2021

Published: March 10, 2021

(C) All rights are reserved by Anand

Aggarwal., et al.

\begin{abstract}
Purpose: The aim of the study was to compare the intraocular pressure (IOP) lowering efficacy and side effect profile of preservative free brimonidine $0.2 \%$ /timolol $0.5 \%$ fixed dose combination (BTFC) versus benzalkonium chloride (BKC) preserved brimonidine $0.2 \% /$ timolol $0.5 \%$ fixed dose combination.

Methods: A prospective, randomized, comparative, 8-week study was conducted on sixty patients of primary open angle glaucoma (POAG) or ocular hypertension. Enrolled patients were randomized into two groups (Group 1 and 2) with thirty patients in each group. Group 1 (Preservative free BTFC) patients were given preservative free brimonidine $0.2 \% /$ timolol $0.5 \%$ fixed dose combination one drop twice daily and Group 2 (BKC preserved BTFC) patients were given benzalkonium chloride preserved brimonidine $0.2 \% /$ timolol $0.5 \%$ fixed dose combination one drop twice daily for 8 weeks, and IOP was recorded at baseline and at 4 week and 8 week visit at 9 am (before instillation of drug) and 11 am (post dose, peak effect). IOP lowering potential, side effect profile was noted at each visit and cost analysis was done for both the study drugs.

Results: There was no statistically significant difference in patient demographics of the two groups. The mean age for Group 1 (Preservative free BTFC) was 62.97 years and for Group 2 (BKC preserved BTFC) was 61.67 years. In Group 1 (Preservative free BTFC), 18 (60\%) were females and in Group 2 (BKC preserved BTFC), 16 (53.33\%) were females. There was no statistical difference between the baseline IOP of both the groups. Significant reduction of IOP from the baseline was seen at both time points, throughout the follow up visits, in both the groups ( $\mathrm{p}<0.00001)$. Mean reduction from the baseline for Group 1 (Preservative free BTFC) was found to be $8.67 \pm 1.30 \mathrm{mmHg}(33.50 \%)$ and for Group 2 (BKC preserved BTFC) was $8.82 \pm 1.98 \mathrm{mmHg}(33.32 \%)$ and the difference between the two groups was statistically insignificant $(\mathrm{p}=0.73)$. Although there was no statistically significant difference in number of each side effect encountered by the patients in both the groups but side effects did show higher tendency in number in Group 2 (BKC preserved BTFC) than in Group 1 (Preservative free BTFC). Using cost minimization analysis, it was found that BKC preserved BTFC costs Rs. $181.89 \pm 5.96(\$ 2.39 \pm 0.27)$ more than Preservative free BTFC to attain similar IOP lowering effect over 8 weeks.

Conclusion: Preservative free $0.2 \%$ Brimonidine $/ 0.5 \%$ Timolol fixed drug combination is an effective, safe and cheaper alternative to BKC preserved $0.2 \%$ Brimonidine/0.5\% Timolol fixed drug combination in medical management of POAG.
\end{abstract}

Keywords: Fixed Dose Combination (BTFC); Benzalkonium Chloride (BKC); Brimonidine

Citation: Anand Aggarwal, et al. "Efficacy and Safety Profile of Preservative Free Brimonidine 0.2\%/Timolol 0.5\% Fixed Dose Combination (BTFC) vs Benzalkonium Chloride (BKC) Preserved Brimonidine 0.2\%/Timolol 0.5\% Fixed Dose Combination: A Prospective Study". Acta Scientific Ophthalmology 4.4 (2021): 129-135. 


\section{Introduction}

Glaucoma is a progressive optic neuropathy characterized by the loss of retinal ganglion cells and their accompanying axons that results in a distinctive appearance of the optic disc and resultant loss of visual function [1]. At present, reduction of IOP is the only evidence-based therapy available for glaucoma and it can be effectively done by the use of topical medications [2]. Monotherapy is often inadequate to achieve the optimal lowering of intraocular pressure. Combination of drugs is hence often necessary to reach the target IOP. Using fixed dose combination reduces the side effects of preservatives due to multiple drops and eases the administration. Also compliance is better with fixed therapy than individual multiple medications [3].

However, preserved medications have become a curse for the glaucoma patients due to the high content of Benzalkonium chloride (BKC) in them, a preservative which has been reigning the ophthalmic industry since 1940s [4]. BKC, a detergent type of preservative is highly cytotoxic [5]. This leads to release of various inflammatory mediators which directly cause damage to cornea and tear film [6]. Higher concentrations of BKC can decrease tear film break-up time (TBUT) by disrupting the lipid component of the tear film leading to tear-film instability [7]. It also leads to destabilisation of the tear film indirectly by reducing the goblet cells density in the conjunctival epithelium [8]. This is especially a matter of concern in glaucoma patients, as they inherently have a reduced rate of basal tear turnover [9].

Thus, patients present with symptoms of ocular surface disease such as burning sensation, irritation, foreign body sensation, discharge, ocular pain, fatigued eyes etc, distinctly affecting the quality of life of patients which has a direct impact on patient compliance. Therefore, the emergence of a new generation of BKC-free anti-glaucoma medications (or anti-glaucoma medications with negligible concentrations of $\mathrm{BKC}$ ) is extremely important [10].

The new Brimonidine/Timolol combination is free from preservative which can improve patient compliance and reduction in ocular side effects caused by the preservatives, especially benzalkonium chloride present in anti-glaucoma drugs.

\section{Methods}

This 8-week, prospective, randomized, open labelled parallel study was conducted on sixty patients of POAG or Ocular Hypertension attending the Outpatient Department of Ophthalmology, Government Medical College, Patiala. All patients were $>18$ years of age, having unilateral or bilateral primary open angle glaucoma or ocular hypertension, having IOP $<32 \mathrm{mmHg}$ in one or both eyes without treatment or after proper washout period of two weeks.

Exclusion criteria included hypersensitivity or contraindication to the study drug, any abnormality preventing reliable applanation tonometry or examination of the ocular fundus or anterior chamber, corneal dystrophy or degeneration, any intraocular inflammation like conjunctivitis, keratitis or uveitis, intraocular surgery $<6$ months before screening, cardiopulmonary conditions like asthma, heart block that preclude safe administration of a topical beta blocker, use of corticosteroids $<30$ days before screening, pregnant or breast-feeding females and progressive retinal/optic nerve damage other than glaucoma.

Patients fulfilling the inclusion criteria and having none of the exclusion criteria were enrolled in the study after obtaining written informed consent. Patients were then randomized into two groups (Groups 1 and 2) with thirty patients in each group. The patients were enrolled after having undertaken written informed consent in accordance with declaration of Helsinki and they were given an option to prematurely exit the study at any time point without having to furnish any reason for doing so. Patients were then randomized into two groups (Groups 1 and 2) with thirty patients in each group. On day 0 , in both groups baseline IOP was recorded in OPD before starting treatment at 9:00 am and 11:00 am. Group 1 patients were then given one drop of fixed dose combination of Preservative free Brimonidine 0.2\%/Timolol 0.5\% twice daily (Brimaze-T; AICE Health care, Bangalore, India) at 9:00 am and 9:00 pm and Group 2 patients were given one drop fixed dose combination of BKC preserved Brimonidine 0.2\%/Timolol 0.5\% twice daily (Combigan; Allergan India Ltd., Bangalore, India) at 9:00 am and 9:00 pm. IOP was again recorded in OPD at 4th week and 8th week of the study at 9:00am, before instillation of study drug and 11:00 am (2 hours post dose, peak effect) after instillation of the study drug. Effectiveness of drug combination was calculated in terms of mmHg fall in mean intraocular pressure using Goldmann Applanation Tonometer. Side effect profile was recorded and cost analysis was done. All observations thus made were compiled on a proforma and subjected to appropriate tests for statistical analysis using SPSS software version 22.0 Chicago, Illinois, USA. The scheme of the current study is shown in figure 1 .

\section{Results}

\section{Patient characteristics}

Sixty patients were enrolled in the study with 30 patients in each group (Group 1 and Group 2). The mean age in Group 1 (Preservative free BTFC) was 62.97 years and for Group 2 (BKC pre- 
Efficacy and Safety Profile of Preservative Free Brimonidine 0.2\%/Timolol 0.5\% Fixed Dose Combination (BTFC) vs Benzalkonium Chloride (BKC) Preserved Brimonidine 0.2\%/Timolol 0.5\% Fixed Dose Combination: A Prospective Study

131

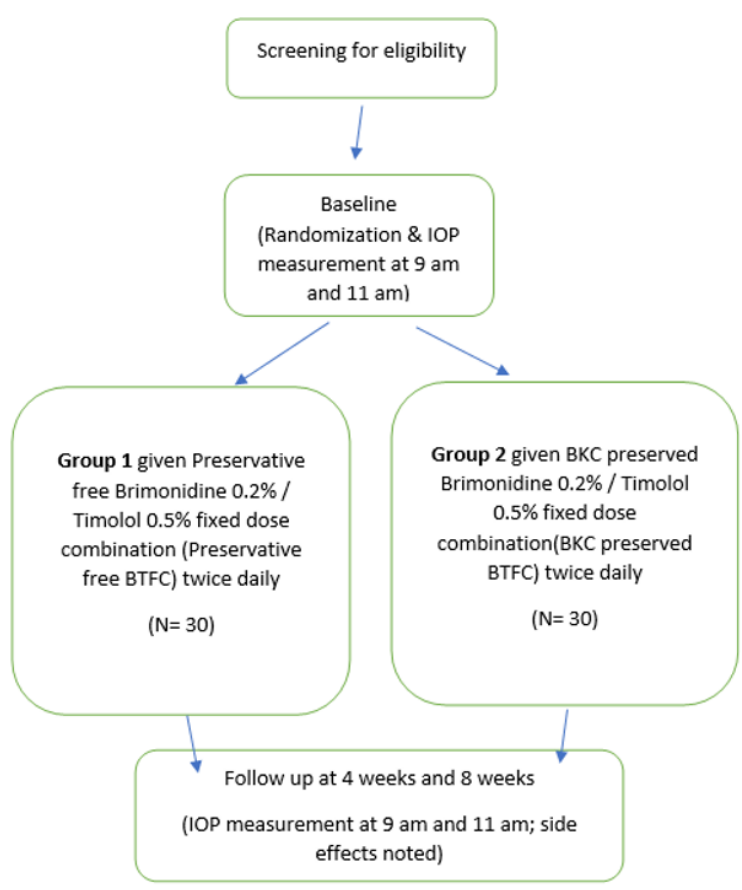

Figure 1: Study design.

\begin{tabular}{|l|c|c|}
\hline \multirow{2}{*}{ Gender } & $\begin{array}{c}\text { Group 1(Preservative } \\
\text { free BTFC) }\end{array}$ & $\begin{array}{c}\text { Group 2(BKC } \\
\text { preserved BTFC) }\end{array}$ \\
\cline { 2 - 3 } & No. of patients (\%) & No. of patients (\%) \\
\hline Female & $18(60 \%)$ & $16(53.33 \%)$ \\
\hline Male & $19(40 \%)$ & $14(46.67 \%)$ \\
\hline Total & $30(100 \%)$ & $30(100 \%)$ \\
\hline
\end{tabular}

Table 2: Gender distribution in both groups.

There was no statistically significant difference in baseline mean IOP at 9 am and 11 am measurements between both the groups ( $p>0.05$ ). Comparing the mean IOP of both the groups at 4 week and 8 week visit at 9 am and 11 am, no statistically significant between-group difference was found ( $p>0.05$ ). (Table 3 )

Mean IOP reduction for Group 1 (Preservative free BTFC) from the baseline, at the end of 8 weeks was found to be $9.27 \pm 1.28$ $\mathrm{mmHg}$ at 9 am and $8.07 \pm 1.48 \mathrm{mmHg}$ at $11 \mathrm{am}$. Similarly, mean IOP reduction for Group 2 (BKC preserved BTFC) from the baseline, at the end of 8 weeks was found to be $9 \pm 1.86 \mathrm{mmHg}$ at 9 am and $8.23 \pm 2.05 \mathrm{mmHg}$ at $11 \mathrm{am}$ (Table 4 ). Mean IOP reduction at each time point in both groups was statistically significant $(p<0.00001)$ (Figure 2).

At the end of 8 weeks, mean decrease from the baseline IOP for Group 1 (Preservative free BTFC) and Group 2 (BKC preserved BTFC) was $8.67 \pm 1.30 \mathrm{mmHg}(33.50 \%)$ and $8.82 \pm 1.98 \mathrm{mmHg}$ (33.32\%) respectively. (Table 5) The intergroup comparison of mean IOP lowering over all time points was statistically insignifi-

served BTFC) was 61.67 years (Table 1). There was no statistical difference between the age of patients in the two groups $(\mathrm{p}=0.54)$. In Group 1 (Preservative free BTFC) 18 (60\%) patients were females and 12 (40\%) were males and in Group 2 (BKC preserved BTFC) $16(53.33 \%)$ patients were females and 14 (46.67\%) were

\begin{tabular}{|l|c|c|}
\hline \multirow{2}{*}{ Age } & $\begin{array}{c}\text { Group 1(Preservative free } \\
\text { BTFC) }\end{array}$ & $\begin{array}{c}\text { Group 2(BKC } \\
\text { preserved BTFC) }\end{array}$ \\
\cline { 2 - 3 } & No. Of patients (\%) & No. Of patients (\%) \\
\hline$\leq 50$ & $2(6.67 \%)$ & $3(10 \%)$ \\
\hline $51-60$ & $9(30 \%)$ & $11(36.67 \%)$ \\
\hline $61-70$ & $17(56.67 \%)$ & $11(36.67 \%)$ \\
\hline $71-80$ & $2(6.67 \%)$ & $5(16.67 \%)$ \\
\hline Total & 30 & 30 \\
\hline Mean & $62.97 \pm 7.37$ & $61.67 \pm 8.96$ \\
\hline Range & $48-78$ & $44-80$ \\
\hline
\end{tabular}

Table 1: Age distribution in both groups

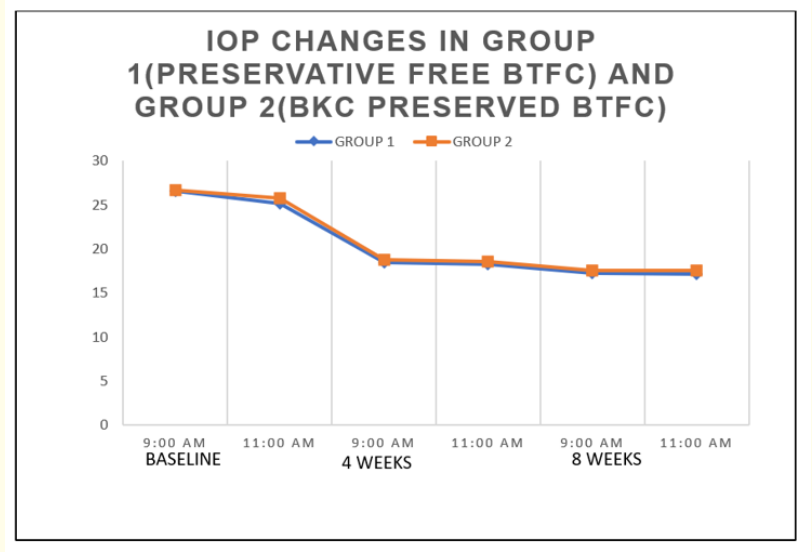

Figure 2

males (Table 2). ( $p=0.97)$.

IOP lowering efficacy 
Efficacy and Safety Profile of Preservative Free Brimonidine 0.2\%/Timolol 0.5\% Fixed Dose Combination (BTFC) vs Benzalkonium Chloride (BKC) Preserved Brimonidine 0.2\%/Timolol 0.5\% Fixed Dose Combination: A Prospective Study

\begin{tabular}{|c|c|c|c|c|c|c|c|}
\hline & Group & $\begin{array}{c}\text { Baseline Mean } \\
\pm \mathrm{SD}(\mathrm{mmHg})\end{array}$ & p value & $\begin{array}{l}\text { Week-4 Mean } \\
\pm \text { SD (mmHg) }\end{array}$ & p value & $\begin{array}{l}\text { Week-8 Mean } \\
\pm S D(\mathrm{mmHg})\end{array}$ & $p$ value \\
\hline \multirow{2}{*}{$\begin{array}{l}9: 00 \\
\mathrm{AM}\end{array}$} & $\begin{array}{c}\text { GROUP } 1 \text { (Preservative free } \\
\text { BTFC) }\end{array}$ & $26.57 \pm 1.63$ & \multirow{2}{*}{0.72} & $18.47 \pm 1.89$ & \multirow{2}{*}{0.66} & $17.3 \pm 1.34$ & \multirow{2}{*}{0.55} \\
\hline & $\begin{array}{c}\text { GROUP } 2 \text { (BKC preserved } \\
\text { BTFC) }\end{array}$ & $26.73 \pm 1.81$ & & $18.77 \pm 2.69$ & & $17.6 \pm 2.09$ & \\
\hline \multirow{2}{*}{$\begin{array}{l}11: 00 \\
\mathrm{AM}\end{array}$} & $\begin{array}{c}\text { GROUP } 1 \text { (Preservative free } \\
\text { BTFC) }\end{array}$ & $25.2 \pm 1.71$ & \multirow{2}{*}{0.25} & $18.23 \pm 1.57$ & \multirow{2}{*}{0.54} & $17.13 \pm 1.22$ & \multirow{2}{*}{0.42} \\
\hline & $\begin{array}{c}\text { GROUP } 2 \text { (BKC preserved } \\
\text { BTFC) }\end{array}$ & $25.77 \pm 1.74$ & & $18.63 \pm 2.73$ & & $17.53 \pm 2.10$ & \\
\hline
\end{tabular}

Table 3: Comparison of mean intraocular pressure of both the groups at various visits.

\begin{tabular}{|l|c|c|c|c|c|}
\hline & Group & $\begin{array}{c}\text { Baseline MEAN } \pm \text { SD } \\
\text { (mmHg) }\end{array}$ & $\begin{array}{c}\text { 8 Weeks MEAN } \pm \\
\text { SD (mmHg) }\end{array}$ & $\begin{array}{c}\text { Reduction in } \\
\text { IOP (mmHg) }\end{array}$ & p value \\
\hline 9:00 AM & $\begin{array}{c}\text { GROUP 1 (Preservative free } \\
\text { BTFC) }\end{array}$ & $26.57 \pm 1.63$ & $17.3 \pm 1.34$ & $9.27 \pm 1.28$ & $<0.00001$ \\
\cline { 2 - 6 } & GROUP 2 (BKC preserved BTFC) & $26.73 \pm 1.81$ & $17.13 \pm 1.22$ & $8.07 \pm 1.48$ & $<0.00001$ \\
\hline 11:00 AM & $\begin{array}{c}\text { GROUP 1 (Preservative free } \\
\text { BTFC) }\end{array}$ & $25.2 \pm 1.71$ & $17.6 \pm 2.09$ & $9 \pm 1.86$ & $<0.00001$ \\
\cline { 2 - 6 } & GROUP 2 (BKC preserved BTFC) & $25.77 \pm 1.74$ & $17.53 \pm 2.10$ & $8.23 \pm 2.05$ & $<0.00001$ \\
\hline
\end{tabular}

Table 4: Mean IOP reduction in both the groups at each time point

\begin{tabular}{|l|c|c|c|c|}
\hline \multicolumn{1}{|c|}{ Group } & \multicolumn{2}{|c|}{ Avg of 9 AM and 11 AM } & $\begin{array}{c}\text { IOP reduction } \\
\text { (mmHg) }\end{array}$ & \% age reduction \\
\hline & Baseline & 8 weeks & $8.67 \pm 1.30$ & $33.50 \%$ \\
\hline $\begin{array}{l}\text { GROUP 1 } \\
\text { (Preservative free } \\
\text { BTFC) }\end{array}$ & $25.88 \pm 1.62$ & $17.22 \pm 1.27$ & $8.82 \pm 1.98$ & $33.32 \%$ \\
\hline $\begin{array}{l}\text { GROUP 2 } \\
\text { (BKC preserved BTFC) }\end{array}$ & $26.47 \pm 2.84$ & $17.57 \pm 2.09$ & & \\
\hline
\end{tabular}

Table 5: Percentage reduction of IOP in both the groups.

cant $(\mathrm{p}=0.73)$.

Side effect profile

In Group 1 (Preservative free BTFC), the most common side effect was ocular hyperaemia (16.67\%) followed by stinging $(6.67 \%)$, itching (6.67\%), foreign body sensation (3.33\%) and increased lacrimation (3.33\%). In Group 2 (BKC preserved BTFC), at 4 week visit, the most common side effect was ocular hyperaemia (20\%), followed by itching (13.33\%), stinging (10\%), foreign body sensation
(6.67\%), and increased lacrimation (3.33\%). At 8 week visit, an increase in number of side effects was found. Ocular hyperaemia being the most common (26.67\%) followed by increased lacrimation (13.33\%), foreign body sensation (13.33\%), itching (13.33\%), stinging (10\%). Total number of side effects at the end of 8 weeks for Group 1 (Preservative free BTFC) was less than Group 2 (BKC preserved BTFC) but the difference was statistically insignificant 
Efficacy and Safety Profile of Preservative Free Brimonidine 0.2\%/Timolol 0.5\% Fixed Dose Combination (BTFC) vs Benzalkonium Chloride (BKC) Preserved Brimonidine 0.2\%/Timolol 0.5\% Fixed Dose Combination: A Prospective Study

133

\begin{tabular}{|l|c|c|c|}
\hline \multirow{2}{*}{ Side effects } & $\begin{array}{c}\text { Group 1 } \\
\text { (Preservative } \\
\text { free BTFC) }\end{array}$ & $\begin{array}{c}\text { Group 2 (BKC } \\
\text { preserved } \\
\text { BTFC) }\end{array}$ & P value \\
\cline { 2 - 4 } & $\mathbf{N ~ ( \% )}$ & $\mathbf{N ~ ( \% )}$ & $\mathbf{( X 2 )}$ \\
\hline $\begin{array}{l}\text { Ocular } \\
\text { hyperaeima }\end{array}$ & $5(16.67 \%)$ & $8(26.67 \%)$ & 0.35 \\
\hline $\begin{array}{l}\text { Increased } \\
\text { lacrimation }\end{array}$ & $1(3.33 \%)$ & $4(13.33 \%)$ & 0.16 \\
\hline $\begin{array}{l}\text { Foreign body } \\
\text { senation }\end{array}$ & $1(3.33 \%)$ & $4(13.33 \%)$ & 0.16 \\
\hline Itching & $2(6.67 \%)$ & $4(13.33 \%)$ & 0.39 \\
\hline Stinging & $2(6.67 \%)$ & $3(10 \%)$ & 0.64 \\
\hline
\end{tabular}

Table 6: Comparison of side effect profile of both the groups at the end of 8 weeks.

$(\mathrm{p}>0.05)$ (Table 6).

\section{Cost analysis}

In our study, we also did volumetric analysis of both the drug formulations by comparing the actual volume, drops per bottle and number of drops per ml of vials (Table 7). From the above parameters, cost for 8 weeks of both the fixed drug combinations was calculated. It was found that BKC preserved BTFC was costlier than Preservative free BTFC, with per eye per day cost of BKC preserved BTFC being Rs $8.42 \pm 0.112$ (\$ $0.11 \pm 0.001)$ and that of Preservative free BTFC being Rs $5.172 \pm 0.059$ ( $\$ 0.07 \pm 0.001$ ). The 8-weekly cost of Preservative free BTFC was found to be Rs $289.63 \pm 2.97$ (\$3.99 \pm 0.06 ) while that of BKC preserved BTFC was Rs $471.52 \pm 6$ (\$ $6.38 \pm 0.31$ ). The percentage reduction of IOP from the baseline was equivalent in both the groups ( $p>0.05$ ). Therefore, applying the cost minimisation analysis by directly comparing the cost incurred with both the drugs for the period of 8 weeks, we observed that the BKC preserved BTFC costs Rs. $181.89 \pm 5.96$ (\$2.39 \pm 0.27$)$ more than Preservative free BTFC to attain similar IOP lowering for a period of 8 weeks (Table 8). (USD-INR conversion $1 \$=72-76 \mathrm{Rs}$ ).

\section{Discussion}

IOP is the only modifiable risk factor for glaucoma which can be effectively controlled with the use of topical anti-glaucoma medications. Topical medications are the mainstay of treatment for POAG and OHT. As most of the topical medications contain preservatives, most common being BKC, long term medical therapy for glaucoma can have a detrimental effect on the ocular surface because of the additive toxic effect of these preservatives. This in turn enhances

\begin{tabular}{|l|c|c|c|c|}
\hline \multicolumn{1}{|c|}{ Drug } & $\begin{array}{c}\text { Volume } \\
\text { (ml) }\end{array}$ & $\begin{array}{c}\text { Drops/ } \\
\text { bottle }\end{array}$ & $\begin{array}{c}\text { Drops/ } \\
\text { ml }\end{array}$ & $\begin{array}{c}\text { Drop size } \\
\text { (ml) }\end{array}$ \\
\hline $\begin{array}{l}\text { Group 1 } \\
\text { (Preservative } \\
\text { free BTFC) }\end{array}$ & $\begin{array}{c}4.98 \pm \\
0.084\end{array}$ & $\begin{array}{c}135.2 \pm \\
1.48\end{array}$ & $\begin{array}{c}27.14 \pm \\
0.65\end{array}$ & $0.0366 \pm$ \\
& & & & \\
\hline $\begin{array}{l}\text { Group 2 (BKC } \\
\text { preserved } \\
\text { BTFC) }\end{array}$ & $4.96 \pm$ & $110.4 \pm$ & $22.26 \pm$ & $0.0446 \pm$ \\
& 0.055 & 1.52 & 0.41 & 0.0009 \\
\hline
\end{tabular}

Table 7: Volumetric analysis.

\begin{tabular}{|l|c|c|c|c|}
\hline \multicolumn{1}{|c|}{ Drug } & $\begin{array}{c}\text { MRP } \\
\text { (RS) }\end{array}$ & $\begin{array}{c}\text { Cost per } \\
\text { day per } \\
\text { eye (RS) }\end{array}$ & $\begin{array}{c}\text { Cost per 8 } \\
\text { weeks per } \\
\text { eye (RS) }\end{array}$ & $\begin{array}{c}\text { Cost } \\
\text { minimisation } \\
\text { analysis }\end{array}$ \\
\hline $\begin{array}{l}\text { Group 1 } \\
\text { (Preservative } \\
\text { free BTFC) }\end{array}$ & 350 & $\begin{array}{c}5.172 \pm \\
0.059\end{array}$ & $\begin{array}{c}289.63 \pm \\
2.97\end{array}$ & \multirow{2}{*}{$181.89 \pm 5.96$} \\
\cline { 1 - 4 } $\begin{array}{l}\text { Group 2 (BKC } \\
\text { preserved } \\
\text { BTFC) }\end{array}$ & 464.79 & $\begin{array}{c}8.42 \pm \\
0.112\end{array}$ & $\begin{array}{c}471.52 \pm \\
6.29\end{array}$ & \\
\hline
\end{tabular}

Table 8: Daily and 8 weekly cost of therapy per eye.

patient discomfort, directly affecting adherence to therapy and patient compliance, causing hindrance in effective IOP control. Therefore, the BKC-free anti-glaucoma medications (or anti-glaucoma medications with minimal concentration of preservatives) have become an integral part of glaucoma therapy in improving quality of life of patient along with providing effective IOP lowering potential.

In our study, after 8 weeks of treatment, mean IOP reduction at the end of 8 weeks for Group 1 (Preservative free BTFC) from the mean baseline IOP of $25.88 \pm 1.63 \mathrm{mmHg}$ was $8.67 \pm 1.30 \mathrm{mmHg}$ (33.50\% reduction). For Group 2 (BKC preserved BTFC) mean IOP reduction from the baseline $\mathrm{IOP}$ of $26.47 \pm 2.84 \mathrm{mmHg}$ was $8.82 \pm$ $1.98 \mathrm{mmHg}$ (33.32\% reduction). At both time measurements i.e., 9 am and $11 \mathrm{am}$, significant reduction in mean IOP from respective baseline $(\mathrm{p}<0.00001)$ was seen throughout the follow ups in both the groups, during the 8 weeks study period.

In 2006, Sherwood., et al. evaluated the efficacy of BTFC in POAG and OHT patients and found its mean IOP reduction to be 4.4-7.6 mmHg from the baseline [11]. In 2007, Arcieri., et al. in a prospective, multicentric, crossover study evaluated the IOP lowering efficacy of BTFC and found the mean IOP lowering of $7.8 \pm$ $1.9 \mathrm{mmHg}(34.3 \pm 8.5 \%)$ from the baseline [12]. In another ran- 
domized parallel group study conducted in patients of POAG and OHT by Nixon., et al. in 2009, the mean IOP reduction by BTFC was found to be $7.7 \mathrm{mmHg}$ (32.3\%) from the baseline [13]. Hommer A., et al. in 2012, in a crossover study found the percentage IOP reduction for $\mathrm{BTFC}$ from the baseline to be $33.6 \% \pm 8.8 \%$ [14]. In 2012, Cheng., et al. estimated the mean IOP reduction of BTFC to be 4.5-6.9 mmHg (28.1\%) [15]. Thus, a significant reduction in IOP with BTFC in both the treatment groups was seen in our study, as in most of the above-mentioned studies.

In the present study, the mean decrease in IOP from baseline was comparable between Group 1 (Preservative free BTFC) and Group 2 (BKC preserved BTFC) at both 9 am and 11 am measurements at 4 week and 8 week study visits. The difference in mean IOP reduction in the two groups was statistically insignificant ( $p$ $=0.73$ ). These findings are consistent with results from previous studies. Wang., et al. in 2013 conducted a meta-analysis to explore the efficacy of eye drops without BKC in treating glaucoma and ocular hypertension. It was found that there was no statistically significant difference between the eye drops with or without BKC, in lowering IOP [16]. Similarly, in 2015, a clinical audit was designed by Goldberg., et al. to examine the impact of BKC-free anti-glaucoma medications on patients with symptoms of OSD. It was found that there was no significant change in IOP from the pre-study levels ( $p$ $=0.105$ ) [17].

In our study, the number of side effects was more in Group 2 (BKC preserved BTFC) than in Group 1 (Preservative free BTFC). The incidence increased in subsequent visit in Group 2 (BKC preserved BTFC), but remained constant in both the visits in Group 1(Preservative free BTFC). Although, at the end of 8 weeks, the difference in number of side effects between both the groups was statistically insignificant ( $p>0.05$ ), Preservative free BTFC has the potential of having a better safety profile in patients requiring long term antiglaucoma medication.

Similarly, in a study conducted by Pisella in 2002, all symptoms were more prevalent with preserved anti-glaucoma eye drops as compared to the preservative-free eye drops: discomfort upon instillation (43\% vs $17 \%$ ) and symptoms between instillations such as burning-stinging ( $40 \%$ vs $22 \%$ ), foreign body sensation $(31 \%$ vs $14 \%$ ), dry eye sensation ( $23 \%$ vs $14 \%$ ), tearing ( $21 \%$ vs $14 \%$ ), and eyelid itching (18\% vs 10\%) [8]. In 2018, a randomized clinical trial was conducted by Aguayo., et al. to evaluate the efficacy, tolerability and safety of preservative free fixed combination of $0.5 \%$ Timolol/0.2\% Brimonidine/2\% Dorzolamide. It was found that preservative free combination was equivalent in terms of efficacy and safety profile $(p>0.05)$ with better patient satisfaction compared to BKC preserved fixed drug combination [18]. Thus, the results of the present study are in accordance with previous studies.

It is believed that benzalkonium chloride enhances drug penetration by disrupting the intercellular junctions within the corneal epithelium therefore, indirectly improving efficacy of the drug. But the results of our study stipulate that the absence of benzalkonium chloride did not have a meaningful effect on efficacy of the Preservative free BTFC, hence, making the point that preservative free BTFC is even more advantageous in patients having intolerability to preserved medications.

We also did small cost analysis of the study drugs to find the economical option out of the two. Applying the cost minimisation analysis by directly comparing the cost incurred with both the drugs for the period of 8 weeks, we observed that the BKC preserved BTFC costs Rs. $181.89 \pm 5.96$ (\$2.39 \pm 0.27 ) more than Preservative free BTFC to attain similar IOP lowering for a period of 8 weeks. Thus, Preservative free BTFC treatment cost was found to be cheaper than that for BKC preserved BTFC.

To the best of our knowledge, this is the first study, from this part of the world, comparing the preservative free $0.2 \%$ Brimonidine $/ 0.5 \%$ Timolol fixed dose combination with BKC preserved $0.2 \%$ Brimonidine $/ 0.5 \%$ Timolol fixed dose combination in terms of efficacy, safety and cost of the study drugs. However, this study is limited by its open label design with limited number of patients. IOP measurements were done on two specific time points instead of a 24-hour diurnal monitoring as the patients denied hospitalisation in absence of any non-ocular disease. Also, the limited 8-week duration of the study did not allow for investigation of long-term effects and safety profile of the study drugs. But the preliminary results of our study show that new Preservative free $0.2 \%$ Brimonidine $/ 0.5 \%$ Timolol fixed dose combination is an effective and safe alternative to BKC preserved $0.2 \%$ Brimonidine $/ 0.5 \%$ Timolol fixed dose combination with lesser cost and assimilated advantages innate to the preservative free topical medications.

\section{Conclusion}

From our study, we conclude that preservative free $0.2 \%$ Brimonidine $/ 0.5 \%$ Timolol fixed drug combination is an effective, safe and cheaper alternative to BKC preserved 0.2\% Brimonidine/0.5\% Timolol fixed drug combination, with potential benefits of being free from deleterious effects caused by preservatives. 


\section{Financial Support and Sponsorship}

Nil.

\section{Bibliography}

1. Weinreb RN and Khaw PT. "Primary open-angle glaucoma". Lancet 363 (2004): 1711-1720.

2. Giuffre I. "Comparative Evaluation of the Efficacy of the Bimatoprost $0.03 \%$, Brimonidine $0.2 \%$, Brinzolamide $1 \%$, Dorzolamide $2 \%$, and Travoprost $0.004 \%$ /Timolol 0.5\%-Fixed combinations in patients affected by open angle glaucoma". Open Journal of Ophthalmology 2.4 (2012): 122.

3. Thomas R., et al. "Glaucoma in India". Glaucoma 12.1 (2003): 81-87.

4. Freeman PD and Kahook MY. "Preservatives in topical ophthalmic medications: historical and clinical perspectives". Expert Review of Ophthalmology 4.1 (2009): 59-64.

5. De Saint JM., et al. "Toxicity of preserved and unpreserved anti-glaucoma topical drugs in an in vitro model of conjunctival cells". Current Eye Research 20.1 (2000): 85-94.

6. Sachdeva M., et al. "Pharmacokinetics of Anti-glaucoma Medications". Journal of Current Glaucoma Practice 5.2 (2011): 2126.

7. Baudouin $\mathrm{C}$ and de Lunardo C. "Short-term comparative study of topical $2 \%$ carteolol with and without benzalkonium chloride in healthy volunteers". British Journal of Ophthalmology 82.1 (1998): 39-42.

8. Pisella PJ., et al. "Prevalence of ocular symptoms and signs with preserved and preservative free glaucoma medication". British Journal of Ophthalmology 86.4 (2002): 418-423.

9. Kuppens EV., et al. "Decreased basal tear turnover in patients with untreated primary open-angle glaucoma”. American Journal of Ophthalmology 120.1 (1995): 1-6.

10. Cvenkel B., et al. "Symptoms and signs of ocular surface disease related to topical medication in patients with glaucoma". Clinical Ophthalmology 9 (2015): 625-631.

11. Sherwood MB., et al. "Twice-daily $0.2 \%$ Brimonidine- $0.5 \%$ Timolol fixed-combination therapy vs monotherapy with Timolol or Brimonidine in patients with glaucoma or ocular hypertension: a 12-month randomized trial". Archives of Ophthalmology 124.9 (2006): 1230-1238.
12. Arcieri ES., et al. "Comparing fixed combination BrimonidineTimolol versus fixed combination Dorzolamide-Timolol in patients with elevated intraocular pressure". Current Medical Research and Opinion 23.4 (2007): 683-689.

13. Nixon DR., et al. "Three-month, randomized, parallel-group comparison of Brimonidine-Timolol versus DorzolamideTimolol fixed combination therapy". Current Medical Research and Opinion 25.7 (2009): 1645-1653.

14. Hommer A., et al. "A double-masked randomized crossover study comparing the effect of Latanoprost/Timolol and Brimonidine/Timolol fixed combination on intraocular pressure and ocular blood flow in patients with primary open-angle glaucoma or ocular hypertension". Journal of Ocular Pharmacology and Therapeutics 28.6 (2012): 569-575.

15. Cheng J-W., et al. "Intraocular pressure lowering effects of commonly used fixed- combination drugs with Timolol: a systematic review and meta-analysis". Plos One 7.9 (2012): e45079.

16. Wang YQ., et al. "Meta-analysis about the efficacy and safety of anti-ocular hypertension eye drops without benzalkonium chloride". Asian Pacific Journal of Tropical Medicine 6.12 (2013): 1004-1008.

17. Goldberg I., et al. "Clinical audit examining the impact of benzalkonium chloride-free anti-glaucoma medications on patients with symptoms of ocular surface disease". Clinical and Experimental Ophthalmology 43.3 (2015): 214-220.

18. Gómez-Aguayo F., et al. "A Phase III Randomized Clinical Trial of a $0.5 \%$ Timolol $+0.2 \%$ Brimonidine $+2.0 \%$ Dorzolamide fixed combination, preservative-free Ophthalmic solution vs. $0.5 \%$ Timolol $+0.2 \%$ Brimonidine $+2.0 \%$ Dorzolamide fixed combination in patients with controlled Primary open-angle glaucoma". Ophthalmology Therapy 7.1 (2018): 145-156.

\section{Assets from publication with us}

- Prompt Acknowledgement after receiving the article

- Thorough Double blinded peer review

- Rapid Publication

- Issue of Publication Certificate

- High visibility of your Published work

Website: www.actascientific.com/

Submit Article: www.actascientific.com/submission.php Email us: editor@actascientific.com

Contact us: +919182824667

Citation: Anand Aggarwal., et al. "Efficacy and Safety Profile of Preservative Free Brimonidine 0.2\%/Timolol 0.5\% Fixed Dose Combination (BTFC) vs Benzalkonium Chloride (BKC) Preserved Brimonidine 0.2\%/Timolol 0.5\% Fixed Dose Combination: A Prospective Study". Acta Scientific Ophthalmology 4.4 (2021): 129-135 